\title{
Does Teriparatide Improve Femoral Neck Fracture Healing: Results From A Randomized Placebo-controlled Trial
}

\author{
Mohit Bhandari MD, PhD, Ling Jin MD, Kyoungah See PhD, \\ Russel Burge PhD, Nigel Gilchrist MBChB, FRACP, Richard Witvrouw MD, \\ Kelly D. Krohn MD, Margaret R. Warner PhD, DVM, Qasim I. Ahmad MD, \\ Bruce Mitlak MD
}

Received: 18 August 2015/Accepted: 2 December 2015/Published online: 1 March 2016

(C) The Association of Bone and Joint Surgeons \& 2016

\begin{abstract}
Background There is a medical need for therapies that improve hip fracture healing. Teriparatide (Forteo ${ }^{\circledR} /$ Forsteo $^{\circledR}$, recombinant human parathyroid hormone) is a bone anabolic drug that is approved for treatment of osteoporosis and glucocorticoid-induced osteoporosis in men and postmenopausal women at high fracture risk. Preclinical and preliminary clinical data also suggest that teriparatide may enhance bone healing.
\end{abstract}

This study was sponsored by Eli Lilly and Company.

The institutions of authors (MB, NG, RW) have received, during the study period, funding from Eli Lilly and Company. One author (MB), or a member of his or her immediate family, has or may receive payments or benefits, during the study period, an amount of less than USD 10,000 from Eli Lilly and Company. One or more of the authors (LJ, KS, RB, KDK, MRW, BM) are employees of Eli Lilly and Company, that provided funding for this study.

One of the authors (QIA) was an employee of Eli Lilly and Company at the time of the study but he no longer is employed by them. All ICMJE Conflict of Interest Forms for authors and Clinical Orthopaedics and Related Research ${ }^{\mathbb{R}}$ editors and board members are on file with the publication and can be viewed on request.

Each author certifies that his or her institution approved the human protocol for this investigation, that all investigations were conducted in conformity with ethical principles of research, and that informed consent for participation in the study was obtained.

This study was conducted at the authors' various institutions.

\section{Bhandari ( $\square)$}

Department of Surgery, McMaster University, 293 Wellington

Street N, Suite 110, Hamilton, ON L8L8E7, Canada

e-mail: bhandam@mcmaster.ca

L. Jin, K. See, R. Burge, K. D. Krohn, M. R. Warner,

Q. I. Ahmad, B. Mitlak

Lilly Research Laboratories, Eli Lilly and Company,

Indianapolis, IN, USA
Questions/purposes We wished to test the hypotheses that treatment with teriparatide versus placebo would improve femoral neck fracture healing after internal fixation as measured by (1) frequency of revision surgery, (2) radiographic fracture healing, and (3) other outcomes including pain control, gait speed, and safety.

Methods We initiated two separate, but identically designed, clinical trials to meet FDA requirements to provide substantial evidence to support approval of a new indication. The two prospective, randomized double-blind, placebo-controlled Phase III studies were designed to evaluate the effect of subcutaneous teriparatide ( $20 \mu \mathrm{g} /$ day $)$ for 6 months versus placebo on fracture healing at 24 months. The trials were conducted concurrently with a planned enrollment of 1220 patients per trial. However, enrollment was stopped owing to very slow patient accrual, and an a priori decision was made to pool the results of those studies for statistical analyses before study completion; pooling was specified in both protocols. Randomization was stratified by fixation (sliding hip screw or multiple cancellous screws) and fracture type (displaced or nondisplaced). An independent Central Adjudication Committee reviewed revision surgical procedures and radiographs. A total of 159 patients were randomized in the two trials (81 placebo, 78 teriparatide). The combined program had very low power to detect the originally

\section{N. Gilchrist}

Canterbury District Health Board and Canterbury Geriatric Medical Research Trust Research, The Princess Margaret Hospital, Christchurch, New Zealand

\section{R. Witvrouw}

Department of Traumatology and Orthopaedics, Sint Jan Hospital, Genk, Belgium 
expected treatment effect but had approximately $80 \%$ power to detect a larger difference of $12 \%$ between treatment groups for risk of revision surgery.

Results The proportion of patients undergoing revision surgery at 12 months was $14 \%$ (11 of 81 ) in the placebo group versus $17 \%$ (13 of 78 ) in the teriparatide group. Central Adjudication Committee review excluded two of these patients treated with placebo from the primary analysis. After exclusions, the proportion of patients who did not undergo revision surgery at 12 months (primary endpoint) was not different between the study and placebo groups, at $88 \%$ in the placebo group (90\% CI, $0.79-0.93$ ) versus $84 \%$ in the teriparatide group $(90 \% \mathrm{CI}, 0.75-0.90$; $p=0.743$ ). There also were no differences between groups in the proportion of patients achieving radiographic fracture healing at 12 months ( $75 \%$ [61 of 81] placebo versus 73\% [57 of 78] teriparatide; odds ratio, $0.89 ; 90 \% \mathrm{CI}$, $0.46-1.72 ; p=0.692$ ) or in measures of pain control (such as pain during ambulation, $92 \%$ [55 of 62] placebo versus 91\% [52 of 57] teriparatide; odds ratio, $0.91 ; 90 \%$ CI, $0.25-3.37 ; p=0.681$ ). The frequency of patients reporting adverse events was $49 \%$ [40 of 81] in the placebo group versus $45 \%$ [35 of 78] in the teriparatide group $(p=0.634)$ during the 6-month treatment period.

Conclusions The small sample size limited this study's power to detect potential differences, and the results are exploratory. With the patients available, teriparatide did not decrease the risk of revision surgery, improve radiographic signs of fracture healing, or decrease pain compared with the placebo. The adverse event data observed were consistent with the teriparatide safety profile. Functional and health outcome data from the studies may help improve our understanding of patients recovering from femoral neck fractures. Further large controlled studies are required to determine the effect of teriparatide on fracture healing.

Level of Evidence Level II, prospective study.

\section{Introduction}

Approximately four million hip fractures are projected to occur worldwide in 2025 [9] and the majority are the result of low-trauma events in the elderly, such as falls [21, 27, 34]. During recovery from hip fracture, most patients experience fracture site pain, reduced mobility, and impaired ability to perform routine daily activities, with a large proportion failing to regain their prefracture functional level after 1 year [6, 24, 25]. Slow recovery after hip fracture has been associated with negative consequences $[26,36,39]$. Thus, there is medical need to improve healing and functional recovery after hip fracture.
Most hip fractures are managed surgically with arthroplasty or with open reduction and internal fixation [10, 16, 23, 35]. Healing complications may occur after either type of surgery, with further surgeries more often required in patients receiving internal fixation [4, 23]. If a pharmacologic therapy could improve hip fracture healing, this may reduce the number of revision surgical procedures, and potentially improve other aspects important for recovery, such as early ambulation.

Locally applied pharmacologic therapies are approved in some countries to accelerate bone healing, but the use of systemic agents for this purpose is controversial [7, 17]. Teriparatide (recombinant human parathyroid hormone [PTH] [1-34]; Forteo ${ }^{\circledR} /$ Forsteo $^{\circledR}$, Eli Lilly and Company, Indianapolis, IN, USA) is approved for treating osteoporosis and glucocorticoid-induced osteoporosis in patients at high fracture risk $[12,29]$. Teriparatide enhanced bone healing in preclinical models $[1,20,28,32]$, and in a controlled clinical trial accelerated radiographic healing of wrist fractures at a dosage of $20 \mu \mathrm{g} /$ day (post hoc analysis) but not $40 \mu \mathrm{g} / \mathrm{day}$ (primary endpoint) [2]. PTH 1-84 also improved fracture healing in a controlled trial of patients with pelvic fractures [30]. Published case reports suggest that teriparatide accelerates bone healing and improves functional recovery after fracture at various skeletal sites $[8,19,31,33,37,38]$.

To further evaluate the potential effect of teriparatide on fracture healing, two identical well-controlled trials were designed to test the hypotheses that teriparatide treatment compared with placebo would (1) decrease the frequency of revision surgery, (2) improve radiographic fracture healing, and (3) improve outcomes including pain control, gait speed, and safety in patients with low-trauma femoral neck fractures repaired with internal fixation.

\section{Patients and Methods}

\section{Study Design}

Two separate, but identically designed, prospective randomized Phase III double-blind, placebo-controlled, multicenter, multinational studies were initiated (NCT01473589 and NCT01473602) in January 2012. The program included two studies to meet FDA requirements for substantial evidence to support approval for a new indication for fracture healing. The primary endpoint was the proportion of patients with successful fracture healing at 24 months. A patient was considered to have successful fracture healing if the following four components of the composite endpoint were met: (1) no revision surgery; (2) radiographic evidence of healing; (3) functional healing 
measured by gait speed; and (4) pain control. The trials included features in common with Fixation Using Alternative Implants for the Treatment of Hip Fractures (FAITH) [11], which compares outcomes in patients treated with cancellous screws versus sliding hip screws, including recommendations for preoperative management and central adjudication of clinical events.

Because accrual in both trials was much slower than expected, enrollment was closed in December 2012. The decision was based on the conclusion that it would take much longer (approximately 10 years or more based on the enrollment rate during the first year) to complete the studies and the goal of the studies could not be achieved in a clinically relevant time. The primary endpoint was amended to revision surgery rate alone at 12 months as decided by the Central Adjudication Committee. Because of the reduced sample size $(<10 \%$ of the plan) and no difference in trial design and implementation, an a priori decision was made to pool the results of those studies before study completion, and pooling was specified in both protocols. All randomized patients were allowed to complete the study.

\section{Participants}

The study enrolled men and postmenopausal women 50 years or older who were ambulatory before sustaining a unilateral low-trauma, femoral neck fracture. Patients received internal fixation surgery (sliding hip screw or multiple cancellous screws) that occurred four or fewer or seven or fewer days after hospitalization for displaced and nondisplaced fractures, respectively. Surgery was not part of the protocol. Other inclusion criteria included no incapacitating disorders except hip fracture and life expectancy of 2 years or more.

Key exclusion criteria included: diseases affecting bone metabolism other than osteoporosis; malignancies (except pretreated carcinoma of the skin or uterine cervix); abnormal baseline serum calcium ( $\geq 10.6 \mathrm{mg} / \mathrm{dL})$, PTH ( $>72 \mathrm{pg} / \mathrm{mL})$, or 25 -hydroxyvitamin $\mathrm{D}(<9.2 \mathrm{ng} / \mathrm{mL})$; concomitant other bone-active drugs; prior treatment with PTH, strontium, BMPs, or growth factors; infection or prior fracture or surgery at the current fracture site; bone grafting or osteotomies; augmentation using degradable cement, hydroxyapatite-coated implants, or noninvasive interventions; and concomitant major injuries of a lower extremity.

The study was compliant with Good Clinical Practice, the Declaration of Helsinki, and other applicable guidelines. Protocols were approved by the appropriate ethical review boards. Signed informed consent was obtained before study procedures were performed.

\section{Randomization}

Within 14 days after internal fixation, patients were randomly assigned to placebo or teriparatide at 1:1 ratio. The randomization was performed separately at each study level, by a table-based randomization scheme with a block size of two using the following factors: site country, fracture type (nondisplaced or displaced), and fixation type (sliding hip screw or multiple cancellous screws) as entered by site personnel.

\section{Description of Experiment}

The study consisted of screening (within 14 days of surgery), 6-month treatment, and 6-month observation periods. Blinded treatment was once-daily subcutaneous injection of 20 $\mu \mathrm{g}$ teriparatide or placebo (identical pen injection devices). All patients received supplemental calcium $(\leq 1000$ $\mathrm{mg} /$ day) and vitamin $\mathrm{D}$ ( $\leq 4000$ International Units/day). No other osteoporosis or bone-active medications were allowed during the 6-month treatment period.

\section{Variables, Outcome Measures, Data Sources, and Bias}

The primary objective was the effect of 6 months of teriparatide treatment versus placebo on the proportion of patients with no revision surgery 12 months after internal fixation of a low-trauma femoral neck fracture. Revision surgery was defined as an additional surgical intervention at the original fracture site as recommended by an investigator or orthopaedic surgeon, except those that were planned at the time of the original procedure. The primary efficacy analysis included the revision surgeries at the original fracture site determined by the Central Adjudication Committee (comprised of four orthopaedic surgeons and one radiologist).

Secondary endpoints included radiographic evidence of fracture healing (determined by the Central Adjudication Committee), pain control (no severe pain during ambulation, during the 24 hours preceding visit, or during weightbearing), recovery of ambulation (gait speed 0.05 $\mathrm{m} /$ second in a $4-\mathrm{m}$ portion of a $7-\mathrm{m}$ walk test; canes or walkers were permitted as needed), composite successful fracture healing (including no revision surgery, radiographic fracture healing, pain control, and ambulation), and safety including adverse events as reported by patients or 


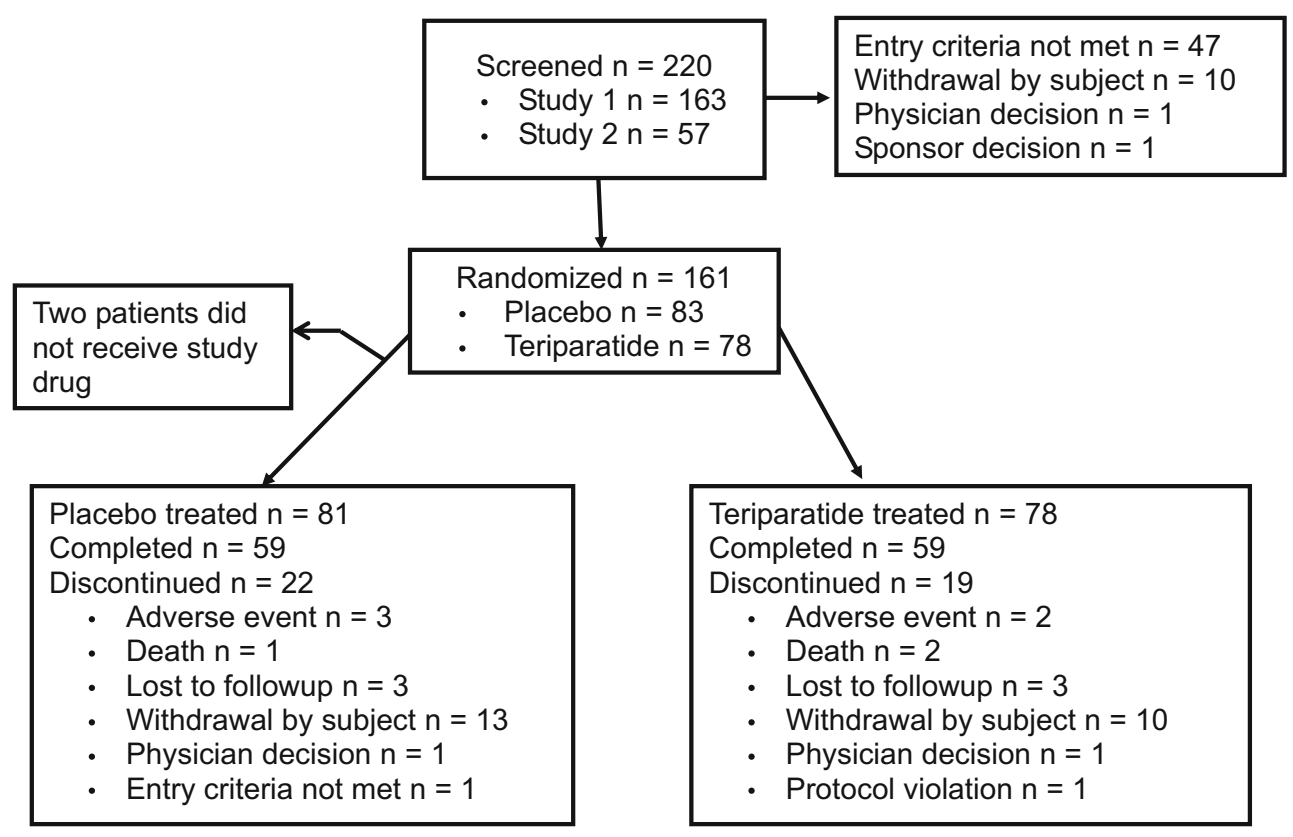

Fig. 1 The CONSORT diagram shows the patient disposition in our study.

investigators. Efficacy endpoints were assessed at 10 weeks, 6 months, and 12 months. The Central Adjudication Committee evaluated serial radiographs for fracture healing using prespecified definitions. Postrevision efficacy data were not included in the analyses.

\section{Study Population}

Of 161 randomized patients in both studies combined from 67 study sites in 18 countries, 159 received the study drug and were included in the full analysis set (78 teriparatide; 81 placebo) (Fig. 1). Four patients (two per treatment group) were judged by the central adjudication committee as having a pertrochanteric fracture. There were no significant differences in patient disposition, including death, discontinuation owing to adverse events, withdrawal, or loss of followup. We did conduct the separated analyses for the data from either study, but because of the small sample size in each (163 patients screened from one trial and 57 patients screened from the other), the results did not change the findings, therefore data from the two trials are not presented separately.

Baseline characteristic were well-balanced between treatment groups including age, sex, fracture type, and fixation type (Table 1). The majority of patients were recruited from Asia or Europe; very few were from the United States.

Overall median drug exposures were 168 days (range, 4-213 days) and 167 days (range, 1-196 days) in the placebo and teriparatide groups, respectively.

\section{Statistical Analysis}

Originally, planned enrollment was 1220 patients per study to detect an $8 \%$ clinically meaningful difference based on the composite endpoint between treatments with $80 \%$ statistical power. Based on published information $[4,5,11]$ and advice from orthopaedic surgeons, $8 \%$ absolute difference in the assumed revision-surgery rates at 24 months (eg, $25 \%$ placebo versus $17 \%$ teriparatide) was considered clinically meaningful.

When the decision was made to suspend the enrollment early, the statistical power was recalculated in the amended protocols before locking the database. With anticipation of approximately 170 randomized patients from both studies, the statistical power was $81 \%$ for detection of a $12 \%$ absolute difference in the revision surgery rates between treatments (eg, 20\% placebo versus $8 \%$ teriparatide) using a one-sided test with $\alpha=0.10$. This assumption was still in line with previous studies reporting revision surgery rates in patients with hip fracture ranging from $0 \%$ to $44 \%$ with a weighted pooled risk of $23 \%(95 \%$ CI, 20\%-26\%) [4, 11].

The proportion of patients with revision surgery at 12 months was compared between treatment groups by comparing Kaplan-Meier estimates of revision surgery at 12 months and using the Z-test statistic based on the chisquare quadratic form using the Greenwood estimator of standard errors $[13,18]$ of the Kaplan-Meier estimates for each treatment. The null hypothesis was that the proportion of patients with no revision surgery at 12 months was not greater in the teriparatide versus placebo group. 
Table 1. Baseline characteristics

\begin{tabular}{|c|c|c|}
\hline Patient characteristic & $\begin{array}{l}\text { Placebo } \\
(\mathrm{n}=81)\end{array}$ & $\begin{array}{l}\text { Teriparatide } \\
(\mathrm{n}=78)\end{array}$ \\
\hline Age (years), median (range) & $70(50-90)$ & $70(50-94)$ \\
\hline \multicolumn{3}{|l|}{ Race, number (\%) } \\
\hline Asian & $39(48)$ & $39(50)$ \\
\hline White & $42(52)$ & $39(50)$ \\
\hline \multicolumn{3}{|l|}{ Sex, number $(\%)$} \\
\hline Female & $60(74)$ & $57(73)$ \\
\hline Male & $21(26)$ & $21(27)$ \\
\hline \multicolumn{3}{|l|}{$\begin{array}{l}\text { American Society of Anesthesiologists } \\
\text { class, number }(\%)\end{array}$} \\
\hline Healthy & $37(46)$ & $33(42)$ \\
\hline Mild systemic disease & $38(47)$ & $36(46)$ \\
\hline Severe systemic disease & $6(7)$ & $9(12)$ \\
\hline \multicolumn{3}{|l|}{ Region, number (\%) } \\
\hline Eastern Asia & $38(47)$ & $37(47)$ \\
\hline Europe & $29(36)$ & $24(31)$ \\
\hline Rest of world & $14(17)$ & $17(22)$ \\
\hline Prior osteoporosis therapy, number (\%) & $7(9)$ & $4(5)$ \\
\hline \multicolumn{3}{|l|}{ Hip fractured, number $(\%)$} \\
\hline Left & $48(59)$ & $47(60)$ \\
\hline Right & $33(41)$ & $31(40)$ \\
\hline \multicolumn{3}{|l|}{$\begin{array}{l}\text { Type of femoral neck fracture } \\
\text { (investigator), number (\%) }\end{array}$} \\
\hline Displaced & $30(37)$ & $30(38)$ \\
\hline Nondisplaced & $51(63)$ & $48(62)$ \\
\hline \multicolumn{3}{|l|}{$\begin{array}{l}\text { Type of femoral neck fracture (CAC), } \\
\text { number }(\%)^{*}\end{array}$} \\
\hline Displaced & $20(26)$ & $21(28)$ \\
\hline Nondisplaced & 57 (74) & $53(72)$ \\
\hline \multicolumn{3}{|l|}{ Fracture cause (investigator), number (\%) } \\
\hline Fall & $74(91)$ & $74(95)$ \\
\hline Spontaneous (stress) fracture & $2(2)$ & $1(1)$ \\
\hline Other & $5(6)$ & $3(4)$ \\
\hline \multicolumn{3}{|l|}{$\begin{array}{l}\text { Internal fixation type (investigator), } \\
\text { number }(\%)\end{array}$} \\
\hline Cancellous screws & $71(88)$ & $72(92)$ \\
\hline Sliding hip screw & $10(12)$ & $6(8)$ \\
\hline \multicolumn{3}{|l|}{$\begin{array}{l}\text { Overall quality of reduction (CAC), } \\
\text { number }(\%)^{\dagger}\end{array}$} \\
\hline Acceptable & $77(96)$ & $76(97)$ \\
\hline Unacceptable & $3(4)$ & $2(3)$ \\
\hline
\end{tabular}

* 77 for placebo and 74 for teriparatide; ${ }^{\dagger} 80$ for placebo and 78 for teriparatide , $\mathrm{CAC}=$ Central Adjudication Committee.

Comparisons between treatment groups for secondary endpoints were made using a Fisher's exact test. To account for patient dropout in longitudinal continuous efficacy analyses, an analysis of covariance model based on the last observation carried forward method was used in some instances.
Evidence of femoral neck fracture healing also was evaluated for the composite endpoint consisting of four components. A patient had evidence of successful healing if all four components were met by the 12 -month visit. Insufficient data for assessment of any component were deemed a fracture-healing failure.

The primary endpoint was tested at a one-sided $\alpha$ level of 0.10 . Other endpoints were tested at a one-sided $\alpha$ level of 0.05 . No adjustments for multiplicity were applied to comparisons of secondary measures, baseline characteristics, or safety parameters.

The data from patients who were randomized and had received the study drug (modified intent-to-treat population) were included in the analyses.

\section{Results}

\section{Revision Surgery}

There was no between-group difference in the proportion of patients undergoing revision surgery at 12 months with the numbers available; $14 \%$ (11 of 81 ) of patients treated with placebo and 17\% (13 of 78) treated with teriparatide had actual or planned revision surgery as reported by the investigators. Two of 11 patients treated with placebo had revision surgery after their femoral neck fractures healed and therefore were excluded from Central Adjudication Committee analyses. Thus, per the Central Adjudication Committee, $11 \%$ (nine of 81 ) of patients treated with placebo and 17\% (13 of 78) treated with teriparatide had actual or planned revision surgery. The proportion of patients with no revision surgery at 12 months (primary endpoint) was $88 \%$ (90\% CI, 0.79-0.93) in the placebo group and $84 \%$ (90\% CI, 0.75-0.90) in the teriparatide group per the Central Adjudication Committee ( $\mathrm{p}=0.743$; Table 2). No treatment group differences were noted in assessments at any time for either investigator or Central Adjudication Committee revision surgery.

The reasons for investigators to recommend revision surgery and the type of surgeries were variable, and no major difference were noted between the groups (Table 3 ). The most common mode of implant failure as reviewed by the Central Adjudication Committee was varus collapse with screw backout in four of 11 patients treated with placebo and seven of 13 treated with teriparatide.

\section{Radiographic Assessment of Fracture Healing}

There were no differences in radiographic healing between the teriparatide and placebo groups at 10 weeks, 6 months, or 12 months (Table 4), with the numbers available. Based 
Table 2. Revision surgery as assessed by the Central Adjudication Committee and reported by the investigator

\begin{tabular}{|c|c|c|c|}
\hline Revision surgery & $\begin{array}{l}\text { Placebo } \\
\text { (Number of patients }=81 \text { ) }\end{array}$ & $\begin{array}{l}\text { Teriparatide } \\
\text { (Number of patients }=78 \text { ) }\end{array}$ & $\mathrm{p}$ value* \\
\hline Analyzed by Central Adjudication Committee & $\mathrm{n}=79^{\dagger}$ & $\mathrm{n}=78$ & \\
\hline Number of patients with revision surgery, $\mathrm{n}(\%)$ at 12 months & $9(11 \%)$ & $13(17 \%)$ & \\
\hline $\begin{array}{l}\text { Proportion of patients with no revision surgery at } 10 \text { weeks } \\
(90 \% \text { Greenwood CI) }\end{array}$ & $\begin{array}{l}99 \% \\
(0.93-1.00)\end{array}$ & $\begin{array}{l}97 \% \\
(0.91-0.99)\end{array}$ & 0.715 \\
\hline $\begin{array}{l}\text { Proportion of patients with no revision surgery at } 6 \text { months } \\
(90 \% \text { Greenwood CI) }\end{array}$ & $\begin{array}{l}96 \% \\
(0.89-0.98)\end{array}$ & $\begin{array}{l}89 \% \\
(0.81-0.93)\end{array}$ & 0.940 \\
\hline $\begin{array}{l}\text { Proportion of patients with no revision surgery at } 12 \text { months } \\
(90 \% \text { Greenwood CI) }\end{array}$ & $\begin{array}{l}88 \% \\
(0.79-0.93)\end{array}$ & $\begin{array}{l}84 \% \\
(0.75-0.90)\end{array}$ & 0.743 \\
\hline Investigator reported & (Number of patients $=81$ ) & (Number of patients $=78$ ) & $\mathrm{p}$ value* \\
\hline Number of patients with revision surgery, $\mathrm{n}(\%)$ at 12 months & $11(14 \%)$ & $13(17 \%)$ & \\
\hline $\begin{array}{l}\text { Proportion of patients with no revision surgery at } 10 \text { weeks } \\
(90 \% \text { Greenwood CI) }\end{array}$ & $\begin{array}{l}99 \% \\
(0.93-1.00)\end{array}$ & $\begin{array}{l}97 \% \\
(0.91-0.99)\end{array}$ & 0.722 \\
\hline $\begin{array}{l}\text { Proportion of patients with no revision surgery at } 6 \text { months } \\
(90 \% \text { Greenwood CI) }\end{array}$ & $\begin{array}{l}94 \% \\
(0.88-0.97)\end{array}$ & $\begin{array}{l}89 \% \\
(0.81-0.93)\end{array}$ & 0.889 \\
\hline $\begin{array}{l}\text { Proportion of patients with no revision surgery at } 12 \text { months } \\
(90 \% \text { Greenwood CI) }\end{array}$ & $\begin{array}{l}85 \% \\
(0.75-0.91)\end{array}$ & $\begin{array}{l}84 \% \\
(0.75-0.90)\end{array}$ & 0.589 \\
\hline
\end{tabular}

* P value based on Z-test statistic from chi-squared quadratic form using Greenwood estimator for standard errors; ${ }^{\dagger}$ two revision surgeries reported by investigators were excluded from Central Adjudication Committee analysis; $n=$ number of patients in category.

Table 3. Revision surgeries reported by investigators

\begin{tabular}{lll}
\hline Category & $\begin{array}{l}\text { Placebo } \\
(\mathrm{n}=11)\end{array}$ & $\begin{array}{l}\text { Teriparatide } \\
(\mathrm{n}=13)\end{array}$ \\
\hline Main reasons to recommend revision surgery* & & \\
Nonunion & 5 & 2 \\
Poor function or mobility & 3 & 4 \\
Painful hardware & 3 & 3 \\
Implant failure & 3 & 2 \\
Avascular necrosis & 1 & 2 \\
Type of revision surgery & & \\
Total arthroplasty & 2 & 6 \\
Hemiarthroplasty & 3 & 4 \\
Implant removal only & 2 & 2 \\
Another internal fixation implant & 2 & 0 \\
Other unspecified procedure & 1 & 0 \\
Revision surgery declined & 1 & 1 \\
\hline
\end{tabular}

* Investigators may report more than one reason for revision surgery.

on the available radiographs, $75 \%$ (61 of 81 ) of patients treated with placebo and $73 \%$ (53 of 78 ) treated with teriparatide had radiographic evidence of fracture healing at 12 months (odds ratio [OR], 0.89; 90\% CI, 0.46-1.72; $\mathrm{p}=0.692$ ). Twelve patients in each group had no radiographic evidence of healing at study completion or early discontinuation, and the remaining patients had no radiograph data (Table 4). In nearly all patients, there was no callus formation at the fracture site during or after fracture healing.

At 12 months or the time of the last available radiographs, the Central Adjudication Committee determined that $14 \%$ ( 10 of 71 ) of patients treated with placebo and $23 \%$ (16 of 69) treated with teriparatide had radiographic healing complications, including femoral neck shortening (six with placebo, 14 with teriparatide), nonunions (three with placebo), malunions (one with placebo), implant breakage or failure (one with teriparatide), and screw migration (two in each group). Avascular necrosis was noted in three patients treated with placebo and five treated with teriparatide.

\section{Other Outcomes}

\section{Pain Control}

With the numbers available, there were no differences between treatment groups in any of the measured pain scores at any time (Table 5) (data not shown). Among the patients who reported analgesic medication use at 6 months, $48 \%$ (33 of 69) of patients treated with placebo and $34 \%$ (23 of 67) treated with teriparatide took analgesic medications $(\mathrm{p}=0.077)$, and the rest of the patients reported not taking analgesic medications. At 12 months, 
Table 4. Radiographic evidence of healing as assessed by the Central Adjudication Committee

\begin{tabular}{|c|c|c|c|c|c|}
\hline \multirow[t]{2}{*}{ Visit/category } & \multirow[t]{2}{*}{ Placebo $(\mathrm{n}=81)$} & \multirow[t]{2}{*}{ Teriparatide $(\mathrm{n}=78)$} & \multicolumn{3}{|c|}{ Treatment comparison } \\
\hline & & & Odds ratio & $90 \% \mathrm{CI}$ & $\mathrm{p}$ value* \\
\hline \multicolumn{6}{|l|}{ Week 10} \\
\hline Number of patients & 81 & 78 & 0.86 & $0.48-1.55$ & 0.733 \\
\hline Evidence of healing ${ }^{\dagger}$, number $(\%)$ & $33(41)$ & $29(37)$ & & & \\
\hline Evidence of no healing ${ }^{*}$, number $(\%)$ & $39(48)$ & $40(51)$ & & & \\
\hline Radiographs missing, number (\%) & $9(11)$ & $9(11)$ & & & \\
\hline \multicolumn{6}{|l|}{ Month 6} \\
\hline Number of patients & 81 & 78 & 0.95 & $0.51-1.77$ & 0.629 \\
\hline Evidence of healing ${ }^{\dagger}$, number $(\%)$ & $57(70)$ & $54(69)$ & & & \\
\hline Evidence of no healing ${ }^{*}$, number $(\%)$ & $16(20)$ & $15(19)$ & & & \\
\hline Radiographs missing, number (\%) & $8(10)$ & $9(12)$ & & & \\
\hline \multicolumn{6}{|l|}{ Month 12} \\
\hline Number of patients (\%) & 81 & 78 & 0.89 & $0.46-1.72$ & 0.692 \\
\hline Evidence of healing ${ }^{\dagger}$, number $(\%)$ & $61(75)$ & $57(73)$ & & & \\
\hline Evidence of no healing ${ }^{*}$, number $(\%)$ & $12(15)$ & $12(15)$ & & & \\
\hline Radiographs missing, number $(\%)$ & $8(10)$ & $9(12)$ & & & \\
\hline
\end{tabular}

* One-sided Fisher's exact test; 'includes patients with radiographs showing healing at the visit or earlier; ${ }^{*}$ includes patients with radiographs showing no healing at the visit and patients who discontinued the study earlier with last radiograph showing no healing.

$43 \%$ (29 of 67 ) of patients treated with placebo and $31 \%$ (19 of 61) treated with teriparatide were still using analgesic medications $(\mathrm{p}=0.108)$.

\section{Gait Speed}

Among the patients who were able to take the gait speed test, $73 \%$ (47 of 64) treated with placebo and $89 \%$ (51 of 57 ) treated with teriparatide could ambulate (gait speed $>$ $0.05 \mathrm{~m} / \mathrm{sec}$ ond) without decline at 12 months (OR, 3.07; 90\% CI, 1.20-8.49; $\mathrm{p}=0.021$ ) (Table 5). The proportions of patients treated with placebo and teriparatide who regained their prefracture ambulatory status were 58\% (43 of 74) and $67 \%$ (49 of 73), respectively (OR, 1.47; 90\% CI, $0.79-2.73 ; \mathrm{p}=0.169)$ at 12 months.

\section{Composite Measure of Successful Fracture Healing}

There were no differences between groups in the proportion of patients who met all four components of successful fracture healing (no revision surgery, radiographic fracture healing, pain control, and ambulation) at 12 months by either Central Adjudication Committee assessment (58\% [46 of 79] with placebo versus 59\% [46 of 78] with teriparatide; OR, 1.03; 90\% CI, 0.58-1.85; p = 0.527) or investigator reporting (57\% [46 of 81] with placebo versus $59 \%$ [46 of 78] with teriparatide; OR, 1.09; 90\% CI, 0.61$1.95 ; \mathrm{p}=0.453)$.
Safety

There were no differences between groups in the proportion of patients reporting adverse events (Table 6), with the numbers available. During the treatment period, three patients in the placebo group and four in the teriparatide group discontinued participation in the study owing to adverse events (gastrointestinal disorder, lethargy, and erythema multiforme in the placebo group; asthenia, pneumonia, subdural hematoma, and blood glucose fluctuation in the teriparatide group, but none was drug-related per investigators).

Two deaths occurred in the teriparatide group during the treatment period (pneumonia, subdural hematoma), and one death occurred in the placebo group during the observation period (myocardial infarction). Per Central Adjudication Committee assessment, these three deaths were not related to the study drug or the original hip fracture.

\section{Discussion}

In current practice, more patients with hip fractures are treated with arthroplasty, which is largely attributable to the lack of viable options to repair hip fractures in a manner that maintains the anatomy (and favorable biomechanics) of a normal hip. We hypothesized that adjunctive therapy to internal fixation of hip fractures with 
Table 5. Fracture site pain and gait speed at 12 months (last observation carried forward)

\begin{tabular}{|c|c|c|c|c|c|}
\hline \multirow[t]{2}{*}{ Categories } & \multirow{2}{*}{$\begin{array}{l}\text { Placebo } \\
(\mathrm{n}=81)\end{array}$} & \multirow{2}{*}{$\begin{array}{l}\text { Teriparatide } \\
(\mathrm{n}=78)\end{array}$} & \multicolumn{3}{|c|}{ Treatment comparison } \\
\hline & & & Odds ratio & $90 \% \mathrm{CI}$ & p value \\
\hline \multicolumn{6}{|l|}{ Pain during ambulation* } \\
\hline Number of patients & 62 & 57 & & & \\
\hline$<7$ and change from baseline $\leq 2$, number $(\%)$ & $55(92)$ & $52(91)$ & & & \\
\hline$\geq 7$ or change from baseline $>2$, number $(\%)$ & $5(8)$ & $5(9)$ & 0.91 & $0.25-3.37$ & 0.681 \\
\hline \multicolumn{6}{|l|}{ During 24 hours preceding visit } \\
\hline Number of patients & 65 & 61 & & & \\
\hline$<7$ and change from baseline $\leq 2$, number $(\%)$ & $55(85)$ & $53(87)$ & & & \\
\hline$\geq 7$ or change from baseline $>2$, number $(\%)$ & $10(15)$ & $8(13)$ & 1.20 & $0.46-3.20$ & 0.457 \\
\hline \multicolumn{6}{|l|}{ On weightbearing } \\
\hline Number of patients & 63 & 58 & & & \\
\hline$<7$ and change from baseline $\leq 2$, number $(\%)$ & $55(87)$ & $52(90)$ & & & \\
\hline$\geq 7$ or change from baseline $>2$, number $(\%)$ & $8(13)$ & $6(10)$ & 1.26 & $0.43-3.87$ & 0.454 \\
\hline \multicolumn{6}{|l|}{ Gait speed ${ }^{\dagger, \S}$} \\
\hline Number of patients & 64 & 57 & & & \\
\hline $\begin{array}{l}\geq 0.05 \mathrm{~m} / \text { second and change from baseline } \\
\geq-0.1 \mathrm{~m} / \text { second, number }(\%)\end{array}$ & $47(73)$ & $51(89)$ & 3.07 & $1.20-8.49$ & 0.021 \\
\hline $\begin{array}{l}<0.05 \mathrm{~m} / \text { second or change from baseline } \\
<-0.1 \mathrm{~m} / \text { second, number }(\%)\end{array}$ & $17(27)$ & $6(11)$ & & & \\
\hline
\end{tabular}

* Fracture site pain was measured using an 11-point numeric rating scale with scores ranging from 0 (no pain) to 10 ( $\geq 7$ severe pain); an increase of $>2$ points was considered clinically meaningful; ${ }^{\dagger}$ poor or worsening functional performance was defined as having a gait speed $<$ $0.05 \mathrm{~m} / \mathrm{second}$ or decrease from baseline of at least $0.1 \mathrm{~m} / \mathrm{second}$; ${ }^{\star}$ one-sided Fisher's exact test; ${ }^{\S}$ baseline was established after the patient became ambulatory as the first not-missing measurement before Month 12; number of patients includes patients with a change from baseline.

Table 6. Adverse events (full-analysis set) reported by investigators

\begin{tabular}{|c|c|c|c|c|c|c|}
\hline \multirow[t]{2}{*}{ Category } & \multicolumn{3}{|c|}{ Treatment phase } & \multicolumn{2}{|c|}{ Observation phase } & \multirow[t]{2}{*}{$\mathrm{p}$ value ${ }^{\dagger}$} \\
\hline & $\begin{array}{l}\text { Placebo } \\
(\mathrm{n}=81) \\
\text { Number }(\%)\end{array}$ & $\begin{array}{l}\text { Teriparatide } \\
(\mathrm{n}=78) \\
\text { Number }(\%)\end{array}$ & p value ${ }^{\dagger}$ & $\begin{array}{l}\text { Placebo } \\
(\mathrm{n}=68) \\
\text { Number }(\%)\end{array}$ & $\begin{array}{l}\text { Teriparatide } \\
(\mathrm{n}=61) \\
\text { Number }(\%)\end{array}$ & \\
\hline Patients with $\geq 1$ adverse events* & $40(49)$ & $35(45)$ & 0.634 & $24(35)$ & $21(34)$ & 1.000 \\
\hline $\begin{array}{l}\text { Patients with } \geq 1 \text { adverse events possibly } \\
\quad \text { related to study drug }\end{array}$ & $5(6)$ & $5(6)$ & 1.000 & 0 & 0 & NA \\
\hline Patients with $\geq 1$ serious adverse events & $7(9)$ & $3(4)$ & 0.329 & $10(15)$ & $3(5)$ & 0.082 \\
\hline
\end{tabular}

* Adverse event $=$ an event that first occurred or worsened during the treatment period after randomization or an event that first occurred or worsened during the observation period; patients may have reported more than one event; ${ }^{\dagger} \mathrm{p}$ value from Fisher's Exact test; NA = not applicable.

teriparatide could provide a biologic advantage compared with surgical internal fixation alone.

We initiated two large Phase III trials to evaluate whether teriparatide could improve clinical outcomes in patients with a low-trauma femoral neck fracture repaired with internal fixation. However, during the first 12 months of recruitment, despite substantial effort, only 161 patients had been randomized in both trials, which were approximately $7 \%$ of the planned study cohort, and few of these patients were from the study sites in the United States. The study sponsor decided to close enrollment early, based on the conclusion that the goal of the studies could not be achieved in a clinically relevant time. Patients who already had enrolled continued in the blinded studies until they completed their 12-month visits.

The inability to enroll patients was multifactorial, including the methodologic aspect requiring daily injections of a study drug, initiation of treatment shortly after the hip fracture in an elderly population, early mobilization of patients in different healthcare systems, and the 
increasing preference of arthroplasty for displaced femoral neck fractures. The outcome of our program highlights the need to further improve methods for conducting studies in this population.

Because the cohort size was smaller than planned, the studies were substantially underpowered to detect the treatment effect included in the original study protocols. Since the treatment effect size was not known with certainty, the study was continued to explore whether a larger treatment effect could have been present. Therefore, the results presented here are exploratory and should be interpreted with caution. However, the results from the pooled studies are unlikely to overestimate a treatment effect as occurred in other trials that were terminated early $[3,14]$.

Pooled results from the 159 patients who received study drugs showed that teriparatide, given for 6 months, did not reduce the frequency of revision surgery or improve radiographic fracture healing at 12 months compared with a placebo. Although there were no between-group differences in measures of pain control, a greater proportion of patients treated with teriparatide was able to ambulate without worsening or regained prefracture ambulatory status at 12 months. However, major differences between groups regarding the functional endpoints were not observed at all times.

The overall proportion of patients undergoing revision surgery in this study was $15 \%$ (24 revision procedures among 159 study patients), which is at the lower end of revision surgery frequencies reported after internal fixation $[4,5]$. Causes for revision surgery in the teriparatide and placebo groups in our study were similar to those reported for internal fixation of hip fractures [22]. The relatively low revision surgery rate in our study may be the result of most fractures being nondisplaced (73\%) and the relatively healthy patient population (eg, community-dwelling, ambulatory, no or mild systemic disease, median age 70 years prefracture). Three deaths were reported in our study, but none was related to study treatment or hip fracture. This is consistent with this being a healthier, more-ambulatory patient population than that observed in general clinical practice [15], as the study entry criteria required that patients have no other incapacitating conditions that are common in the elderly and also have the ability to consent for the study.

Systemic therapy with teriparatide has been shown to improve healing in preclinical fracture models $[1,20,28$, 32], in clinical studies of wrist fractures [2], and in case reports $[8,19,31,33,37,38]$. However, the results from these pooled trials revealed no treatment effect of teriparatide versus placebo in the rates of revision surgery or radiographic fracture healing in femoral neck fractures. Reasons for the lack of treatment effect are speculative.
Possibly, teriparatide does not have a treatment effect in this context or the sample size was too small to detect a difference in revision surgery. Additionally, plain radiographs obtained at the selected intervals may be too crude for evaluation of femoral neck fracture healing, but it was a tradeoff with consideration of limiting radiation exposure during the study.

Findings from a negative trial are reported here, which improves transparency on the design and performance in pharmacologic trials with patients with hip fracture and potentially may limit publication bias. Additionally several study design elements are reported including methodologic rigor in design and several safeguards that ensured patient randomization and blinding, independent blinded central clinical outcomes adjudication, and use of a patient-important primary outcome measure. The study also is one of only a few well-controlled studies of clinical outcomes with a systemically active biologic drug in patients with fracture. Although preclinical studies using PTH in animal models are promising $[1,20,28,32]$ and sporadic case reports of humans $[8,19,31,33,37,38]$ showed an anecdotal benefit of teriparatide in various fractures, there were no well-controlled clinical trials to support the hypothesis that teriparatide improve fracture healing and our study with a much-reduced sample size showed no such benefit. Thus, the effect of teriparatide on fracture healing remains uncertain. The safety results from this study did not change the benefit-risk assessment of teriparatide, an approved bone anabolic agent for treatment of osteoporosis in men and in women who are postmenopausal at high fracture risk. Therefore teriparatide remains a treatment option for elderly patients with lowtrauma hip fractures who are at high risk for subsequent fractures.

Acknowledgments We thank the patients, their families, study sites, and investigative personnel; and Lori Kornberg $\mathrm{PhD}$, and Derek Welsch, for providing editorial and writing support (both from INC Research, Raleigh, NC, USA). We also thank the following study investigators: Study NCT01473589 - Clinicaltrials.gov code, Taiwan: Jinn Lin, Yu-Ping Su, Ching-Hou Ma, Yang-Hwei Tsuang, ChihHung Chang, Kui-Chou Huang; Japan: Takao Mae, Kazuyoshi Asami, Kunihiro Sensui, Jun Kitahara, Satoshi Iida, Yuji Mogami, Masayuki Ito, Masafumi Machida, Kazuhiko Ihara, Shusuke Ota, Hiroyuki Kakimaru, Masanobu Saito, Yasutaka Takagi, Joji Nagase, Yoshitada Harada, Takeharu Tonai, Hiroshi Akaogi, Tsuyoshi Ohishi, Toru Endo, Hideki Moriya, Satoshi Mori; Australia: Peter R. Ebeling; New Zealand: Nigel Gilchrist, J. Singh; India: V. Shah, S. Babhulkar; Israel: Elena Segal, Joseph Foldes; Canada: D. Martin, C. Lindsay; USA: M. Spiegel, T. Dipasquale: Denmark: Lars Borris; Latvia: Sandris Petronis, Maris Zambrans; Lithuania: Donatas Senkanec; Spain: Miguel Angel Froufre, Josep María Muñoz Vives, Enrique Guerado, Esteban Jodar Gimeno, Jorge Malouf Sierra, Xavier Nogues Solan, Juan Oscar Romanillos, Francisco Jose Tarazona Santabalbina; Sweden: Ewa Waern; South Korea: Kyu Hyun Yang, Young Kyun Lee, Young Wan Moon, Jae-Suk Chang, Yong Chan Ha.; and Study NCT01473602 - clinicaltrials.gov code, USA: R. Olson, K. Shrock, 
D.R. Dziadosz; Belgium: Joris Callens, Valerie Gangji, Richard Witvrouw; Germany: Felix Bonnaire; Hungary: Vilmos Halmai, Katalin Kudlak, Katalin Nagy, Janos Aurel Simonka, Robert Szody, Beata Zsiska; Netherlands: Martijn Poeze, Sven Van Helden; Romania: Dan Lucaciu, Gheorghe Popescu; South Korea: Kee Hyung Rhyu, Byung Woo Min, Seung Beon Han, Ji Wan Kim, Ye Yeon Won.

\section{References}

1. Alkhiary YM, Gerstenfeld LC, Krall E, Westmore M, Sato M, Mitlak BH, Einhorn TA. Enhancement of experimental fracturehealing by systemic administration of recombinant human parathyroid hormone (PTH 1-34). J Bone Joint Surg Am. 2005;87:731-741.

2. Aspenberg P, Genant HK, Johansson T, Nino AJ, See K, Krohn K, García-Hernández PA, Recknor CP, Einhorn TA, Dalsky GP, Mitlak BH, Fierlinger A, Lakshmanan MC. Teriparatide for acceleration of fracture repair in humans: a prospective, randomized, double-blind study of 102 postmenopausal women with distal radial fractures. J Bone Miner Res. 2010;25:404-414.

3. Bassler D, Briel M, Montori VM, Lane M, Glasziou P, Zhou Q, Heels-Ansdell D, Walter SD, Guyatt GH; STOPIT-2 Study Group, Flynn DN, Elamin MB, Murad MH, Abu Elnour NO, Lampropulos JF, Sood A, Mullan RJ, Erwin PJ, Bankhead CR, Perera R, Ruiz Culebro C, You JJ, Mulla SM, Kaur J, Nerenberg KA, Schünemann H, Cook DJ, Lutz K, Ribic CM, Vale N, Malaga G, Akl EA, Ferreira-Gonzalez I, Alonso-Coello P, Urrutia G, Kunz R, Bucher HC, Nordmann AJ, Raatz H, da Silva SA, Tuche F, Strahm B, Djulbegovic B, Adhikari NK, Mills EJ, Gwadry-Sridhar F, Kirpalani H, Soares HP, Karanicolas PJ, Burns KE, Vandvik PO, Coto-Yglesias F, Chrispim PP, Ramsay T. Stopping randomized trials early for benefit and estimation of treatment effects: systematic review and meta-regression analysis. JAMA. 2010;303:1180-1187.

4. Bhandari M, Devereaux PJ, Swiontkowski MF, Tornetta P 3rd, Obremskey W, Koval KJ, Nork S, Sprague S, Schemitsch EH, Guyatt GH. Internal fixation compared with arthroplasty for displaced fractures of the femoral neck: a meta-analysis. $J$ Bone Joint Surg Am. 2003;85:1673-1681.

5. Bhandari M, Tornetta P 3rd, Hanson B, Swiontkowski MF. Optimal internal fixation for femoral neck fractures: multiple screws or sliding hip screws? J Orthop Trauma. 2009;23:403407.

6. Binder EF, Brown M, Sinacore DR, Steger-May K, Yarasheski KE, Schechtman KB. Effects of extended outpatient rehabilitation after hip fracture: a randomized controlled trial. JAMA. 2004;292:837-846.

7. Brandi ML. Healing of the bone with anti-fracture drugs. Expert Opin Pharmacother. 2013;14:1441-1447.

8. Chintamaneni S, Finzel K, Gruber BL. Successful treatment of sternal fracture nonunion with teriparatide. Osteoporos Int. 2010;21:1059-1063.

9. Cooper C, Campion G, Melton LJ 3rd. Hip fractures in the elderly: a world-wide projection. Osteoporos Int. 1992;2:285289.

10. Dijkman BG, Kooistra BW, Pemberton J, Sprague S, Hanson BP, Bhandari M. Can orthopedic trials change practice? Acta Orthop. 2010;81:122-125.

11. FAITH Investigators. Fixation using alternative implants for the treatment of hip fractures (FAITH): design and rationale for a multi-centre randomized trial comparing sliding hip screws and cancellous screws on revision surgery rates and quality of life in the treatment of femoral neck fractures. BMC Musculoskelet Disord. 2014;15:219.

12. Forteo ${ }^{\circledR}$ [package insert]. Indianapolis, IN, USA: Eli Lilly and Company; 2012. Available at: http://pi.lilly.com/us/forteo-pi.pdf. Accessed November 24, 2015.

13. Greenwood M. The natural duration of cancer. London, England: His Majesty's Stationery Office, Reports on Public Health and Medical Subjects, No. 33. 1926

14. Guyatt GH, Briel M, Glasziou P, Bassler D, Montori VM. Problems of stopping trials early. BMJ. 2012;344:e3863. Erratum in $B M J .2014 ; 348: 319$.

15. Hebert-Davies J, Laflamme GY, Rouleau D, HEALTH and FAITH investigators. Bias towards dementia: are hip fracture trials excluding too many patients? A systematic review. Injury. 2012;43:1978-1984.

16. Jain NB, Losina E, Ward DM, Harris MB, Katz JN. Trends in surgical management of femoral neck fractures in the United States. Clin Orthop Relat Res. 2008;466:3116-3122.

17. Kamiya N. The role of BMPs in bone anabolism and their potential targets SOST and DKK1. Curr Mol Pharmacol. 2012;5:153-163.

18. Klein JP, Moeschberger ML. Survival Analysis: Techniques for Censored and Truncated Data. 2nd ed. New York, NY: Springer; 2005.

19. Knecht TP. Teriparatide and fracture healing in cortical bone. Endocr Pract. 2004;10:293.

20. Komrakova M, Stuermer EK, Werner C, Wicke M, Kolios L, Sehmisch S, Tezval M, Daub F, Martens T, Witzenhausen P, Dullin C, Stuermer KM. Effect of human parathyroid hormone hPTH (1-34) applied at different regimes on fracture healing and muscle in ovariectomized and healthy rats. Bone. 2010;47:480 492.

21. Koval KJ, Aharonoff GB, Rokito AS, Lyon T, Zuckerman JD. Patients with femoral neck and intertrochanteric fractures: are they the same? Clin Orthop Relat Res. 1996;330:166-172.

22. Leonardsson O, Sernbo I, Carlsson A, Akesson K, Rogmark C. Long-term follow-up of replacement compared with internal fixation for displaced femoral neck fractures: results at ten years in a randomised study of 450 patients. J Bone Joint Surg Br. 2010;92:406-412.

23. Lu-Yao GL, Keller RB, Littenberg B, Wennberg JE. Outcomes after displaced fractures of the femoral neck: a meta-analysis of one hundred and six published reports. J Bone Joint Surg Am. 1994;76:15-25.

24. Magaziner J, Hawkes W, Hebel JR, Zimmerman SI, Fox KM, Dolan M, Felsenthal G, Kenzora J. Recovery from hip fracture in eight areas of function. J Gerontol A Biol Sci Med Sci. 2000;55:M498-507.

25. Magaziner J, Simonsick EM, Kashner TM, Hebel JR, Kenzora JE. Predictors of functional recovery one year following hospital discharge for hip fracture: a prospective study. J Gerontol. 1990;45:M101-107.

26. Magaziner J, Wehren L, Hawkes WG, Orwig D, Hebel JR, Fredman L, Stone K, Zimmerman S, Hochberg MC. Women with hip fracture have a greater rate of decline in bone mineral density than expected: another significant consequence of a common geriatric problem. Osteoporos Int. 2006;17:971-977.

27. Michelson JD, Myers A, Jinnah R, Cox Q, Van Natta M. Epidemiology of hip fractures among the elderly: risk factors for fracture type. Clin Orthop Relat Res.1995;311:129-135.

28. Mognetti B, Marino S, Barberis A, Martin AS, Bala Y, Di Carlo F, Boivin G, Barbos MP. Experimental stimulation of bone healing with teriparatide: histomorphometric and microhardness analysis in a mouse model of closed fracture. Calcif Tissue Int. 2011;89:163-171. 
29. Neer RM, Arnaud CD, Zanchetta JR, Prince R, Gaich GA, Reginster JY, Hodsman AB, Eriksen EF, Ish-Shalom $\mathrm{S}$, Genant HK, Wang O, Mitlak BH. Effect of parathyroid hormone (1-34) on fractures and bone mineral density in postmenopausal women with osteoporosis. $N$ Engl J Med. 2001;344:1434-1441.

30. Peichl P, Holzer LA, Maier R, Holzer G. Parathyroid hormone 1-84 accelerates fracture-healing in pubic bones of elderly osteoporotic women. J Bone Joint Surg Am. 2011;93:15831587.

31. Resmini G, Iolascon G. 79-year-old post-menopausal woman with humerus fracture during teriparatide treatment. Aging Clin Exp Res. 2007;19(4 suppl):30-31.

32. Rowshan HH, Parham MA, Baur DA, McEntee RD, Cauley E, Carriere DT, Wood JC, Demsar WJ, Pizarro JM. Effect of intermittent systemic administration of recombinant parathyroid hormone (1-34) on mandibular fracture healing in rats. J Oral Maxillofac Surg. 2010;68:260-267.
33. Rubery P, Bukata SV. Teriparatide may accelerate healing in delayed unions of type III odontoid fractures: a report of 3 cases. J Spinal Disord Tech. 2010;23:151-155.

34. Sambrook P, Cooper C. Osteoporosis. Lancet. 2006;367:20102018.

35. Shah AK, Eissler J, Radomisli T. Algorithms for the treatment of femoral neck fractures. Clin Orthop Relat Res. 2002;399:28-34.

36. van Staa TP, Leufkens HG, Cooper C. Does a fracture at one site predict later fractures at other sites? A British cohort study. Osteoporos Int. 2002;13:624-629.

37. Yu CT, Wu JK, Chang CC, Chen CL, Wei JC. Early callus formation in human hip fracture treated with internal fixation and teriparatide. J Rheumatol. 2008;35:2082-2083.

38. Zhang D, Potty A, Vyas P, Lane J. The role of recombinant PTH in human fracture healing: a systematic review. J Orthop Trauma. 2014;28:57-62.

39. Zuckerman JD. Hip fracture. N Engl J Med. 1996;334:15191525. 